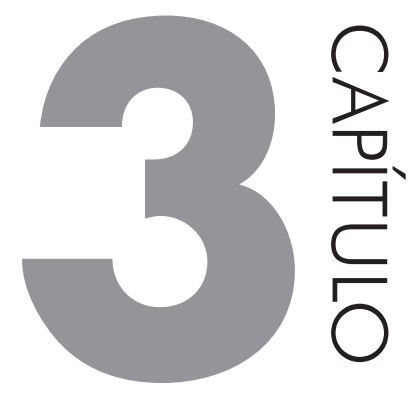

\title{
DAS INVESTIGAÇÕES VARIACIONISTAS ÀS VARIADAS INTERFACES: percursos na análise de fenômenos morfossintáticos
}

SILVIA RODRIGUES VIEIRA ${ }^{1}$

\section{CONSIDERAÇÕES INICIAIS}

Uma vida acadêmica e seus resultados científicos revelam uma constante construção, um fazer e refazer de alta complexidade; experiência complexa, porque reúne, a um só tempo, a minúcia de quem precisa do detalhe (sem perder a essência da assunção de princípios), mas também o olhar de quem persegue o alcance de generalizações. Olhar para as experiências acadêmicas pregressas pode ser um excelente exercício de avaliação que, se bem empreendido, faz ver não somente que há sempre algo por fazer, que o conhecimento escapa pelos dedos e que é isso que instiga sempre mais o espírito pesquisador, mas também que a construção de ideias, por mais díspares e diversificadas que possam parecer, tem

\footnotetext{
1 Destacar as influências de minha querida orientadora, escolhendo um aspecto específico ou resumindo as pesquisas que compartilhamos, foi tarefa de que não consegui dar conta. Resolvi, então, trilhar um caminho menos acadêmico e registrar a diversidade de (sub)áreas que, em alguma medida, refletem estágios de nossa convivência. Esse exercício deixou mais do que claro que tudo que faço tem origem em algum momento de nossa parceria, que é mais do que acadêmica, tem tons "rimados" de maternidade, amizade e gosto de eternidade.
} 
sempre uma raiz, um traço unificante de relações e correlações, dentre as quais as não acadêmicas podem ser as mais motivadoras e instigantes. Trata-se de um exercício nem sempre científico, mas certamente eivado de humanidade.

Este texto persegue o desejo de fazer o referido exercício. Nessa empreitada, constitui-se acadêmico, de um lado, porque parte de diversos trabalhos científicos e busca apresentar resultados relevantes no tratamento dos temas em questão, sobretudo os da concordância verbal e da ordem dos clíticos pronominais; extra acadêmico, de outro, porque declaradamente assume por ponto de partida destacar, nas diversas etapas, os frutos da orientação e amizade construída ao longo dos anos na UFRJ (e, a contar da graduação, lá se vão 25!) com a Professora homenageada desta obra, Silvia Figueiredo Brandão.

Qual é, então, o objetivo deste texto? Destacar diversas interfaces e desdobramentos dos estudos por mim desenvolvidos até aqui, em várias frentes de trabalho, reconhecendo que, em cada etapa da trajetória percorrida, se encontram presentes, direta ou indiretamente, as influências da orientação recebida, desde o Mestrado até as parcerias dos dias de hoje. Uma significativa trajetória de aprendizado e partilha, fruto de um crescente desejo de dar conta do objeto em análise e fazer sempre mais e melhor.

\section{ANÁLISE VARIACIONISTA E A GEOGRAFIA LINGUÍSTICA: O CASO DA CONCORDÂNCIA VERBAL DE $3^{\mathrm{a}}$ PESSOA NO NORTE FLUMINENSE (OU: SILVIA BRANDÃO, DA DIALECTÓLOGA EM MIM)}

Variação, Morfossintaxe, Ensino. Os interesses inicialmente reunidos em torno do tema da concordância verbal de $3^{\mathrm{a}}$ pessoa plural no âmbito do Mestrado (VIEIRA, 1995) encontraram, nos métodos da Geografia Linguística - com o propósito inicial de contribuir com a elaboração do Atlas Etnolinguístico dos Pescadores do Estado do Rio de Janeiro/APERJ -, a oportunidade de experimentar os procedimentos metodológicos mais genuínos para a descrição etnográfica e linguística de uma comunidade de fala: a observação in locu, a pesquisa de campo, a transcrição de entrevistas sociolinguísticas, a coleta de dados, a associação de métodos geolinguísticos e sociolinguísticos (experimentadas já na iniciação científica), a construção de cartas morfossintáticas (cf. MACHADO VIEIRA; VIEIRA, 2006). E tudo isso no Norte do Estado do Rio de Janeiro, com a fala de indivíduos sem escolaridade. A investigação sócio-geolinguística da concordância permitiu conhecer melhor o comportamento das chamadas variedades populares do Português do Brasil, cujas feições puderam oportunamente ser contrastadas às referentes à fala culta urbana mais costumeiramente caracterizada no Brasil.

Os resultados da investigação da concordância verbal de $3^{a}$ pessoa do plural na chamada fala popular possibilitaram ver e deixar ver - conforme proposta de 
Lucchesi; Baxter; Silva (2009, p. 348) - que, no continuum de polarização Sociolinguística, não marcar plural em verbos de $3^{a}$ pessoa identifica estratos que vão do mais rural e não escolarizado, com índices inexpressivos de marcação de plural, aos mais urbanos e escolarizados, com uma regra semicategórica de concordância padrão.

Nos dias atuais, conforme demonstram os primeiros frutos do Projeto internacional Estudo comparado da concordância nas variedades africanas, brasileiras $e$ europeias do Português ${ }^{2}$, Vieira; Bazenga (2013) demonstram que os índices de concordância brasileiros, especificamente os urbanos, se localizam, na porção de um continuum de marcação de variedades internacionais do Português, como a parte mais variável (em comparação com os dados das variedades europeia e são-tomense). Trata-se de uma regra variável, ainda que em porções mais discretas se comparada ao que se verifica em variedades mais populares e/ou isoladas, em contraste com o comportamento também variável (com menor expressividade) da referida variedade africana e com o comportamento (semi)categórico do Português Europeu.

Conforme se pode observar na figura a seguir, os padrões de uso da chamada concordância verbal na fala de não escolarizados do Rio de Janeiro em comparação à dos altamente escolarizados delineiam os extremos do referido continuum, proposto por Lucchesi; Baxter; Silva (2009).

\begin{tabular}{|c|c|c|c|}
\hline [+ marcas] & & & [- marcas] \\
\hline $\begin{array}{c}\text { Urbano } \\
\text { Altamente escolarizado }\end{array}$ & $\begin{array}{c}\text { Urbano } \\
\text { Moderadamente } \\
\text { escolarizado }\end{array}$ & $\begin{array}{c}\text { Urbano } \\
\text { Analfabeto }\end{array}$ & $\begin{array}{l}\text { Rural/Urbano } \\
\text { Analfabeto }\end{array}$ \\
\hline $\begin{array}{c}94 \% \text { (GRACIOSA, 1991) } \\
\text { 97,8\% (VIEIRA; } \\
\text { BAZENGA, 2013) }\end{array}$ & $\begin{array}{c}\text { 73\% (SCHERRE; } \\
\text { NARO, 1997) } \\
\text { 89\% (VIEIRA; } \\
\text { BAZENGA, 2013) }\end{array}$ & 48\% (NARO, 1981) & $38 \%$ (VIEIRA, 1995) \\
\hline
\end{tabular}

Figura 1 Continuum de marcação de pluralidade em verbos de P6 consoante os traços rural / urbano e de escolaridade em variedades do Rio de Janeiro.

Fonte: Vieira; Bazenga (2015: 61) com adaptação.

Dos primeiros resultados relativos às variedades populares fluminenses (VIEIRA, 1995) aos estudos de natureza contrastiva de variedades internacionais

\footnotetext{
2 Projeto que coordenei (em parceria com a Professora Maria Antónia Mota), por indicação da homenageada, na fase inicial - Projeto CAPES/ICTII - e coordeno em parceria com a própria Silvia Brandão na fase atual, como Projeto ALFAL 21.
} 
(VIEIRA; BAZENGA, 2013), fica hoje a evolução de resultados que, em plena expansão de dados e amostras, permitiram o debate relativo ao estatuto das variedades do Português - unindo os resultados da marcação verbal de $3^{\text {a }}$ pessoa aos da concordância nominal (BRANDÃO, 2013) - em Vieira; Brandão (2014), o que será retomado na próxima seção.

\section{ANÁLISE VARIACIONISTA E ABORDAGEM CONTRASTIVA: CARACTERIZAÇÃO DE VARIEDADES DO PORTUGUÊS (OU: SILVIA BRANDÃO, DA SOCIOLINGUISTA COMPARATIVISTA EM MIM)}

Seja na concordância verbal, seja na ordem dos clíticos pronominais, a abordagem contrastiva de detalhados resultados variacionistas, consoante variáveis linguísticas e extralinguísticas, rendeu produtivos resultados. Com base em projetos de natureza comparativa (a começar pelo VARPORT, também coordenado pela homenageada), buscou-se delimitar opções preferenciais, tendências sistemáticas de realização de variantes, ou o que se intitula, em determinados quadros interpretativos, tipos ou parâmetros linguísticos.

Esse empreendimento teve início com a comparação das variedades brasileiras (PB), europeias (PE) e moçambicanas (PM) no que se refere ao instigante tema da colocação pronominal. Em trabalho de Doutorado, Vieira (2002) perseguiu o objetivo da análise contrastiva de resultados, que agora passava do foco das variedades regionais do Norte Fluminense ao das internacionais (considerando Brasil/Rio de Janeiro, Portugal/Lisboa e Moçambique/Maputo). A flagrante dificuldade da ausência de amostras europeias e africanas do Português constituídas segundo critérios de estratificação semelhantes aos empregados nas pesquisas brasileiras não impediu o olhar detalhado, consoante coleta, codificação, quantificação e tratamento estatístico das ocorrências, para a interpretação do estatuto de cada variedade quanto aos grupos de fatores controlados.

A conhecida diferença de comportamento na fala do PB e do PE - com preferência pela colocação pós-verbal (deu-me) e clara atuação dos elementos proclisadores no PE (não me deu), ao contrário da ampla preferência pela colocação pré-verbal (me deu) e a presença da pós-verbal apenas em estruturas e contextos particulares (encontrá-lo; chama-se) no $\mathrm{PB}$ - pôde ser originalmente aferida em grande número de dados contemporâneos e, ainda, contrastada com os padrões de uso na modalidade escrita culta detectada a partir de textos jornalísticos, sobretudo crônicas. Em meio a essa oposição, Vieira (2002) atestou o comportamento vacilante de dados da variedade moçambicana, com expressiva quantidade de ocorrências de colocação pós-verbal mesmo na presença de proclisadores (que chama-se).

No âmbito da ordem dos clíticos em complexos verbais, um detalhado tratamento de variáveis linguísticas e extralinguísticas permitiu não só aferir o com- 
portamento particular da variedade brasileira $(\mathrm{PB})$, mas também o caráter intermediário da variedade moçambicana (PM) em relação ao $\mathrm{PB}$ e ao $\mathrm{PE}$, tendo manifestado este dada preferência pela ênclise à primeira forma verbal. Com o tratamento qualitativo das ocorrências, o estudo indicou a singularidade do PB no uso da chamada "próclise à segunda forma verbal" (pode sempre se refletir; pode sempre me dar), embora tenha demonstrado a necessidade de estudos que particularizem a análise por tipo de pronome átono. Nesse sentido, os dados do clítico se puderam ser considerados reservadamente, de modo a isolar o indeterminador, com preferência pela adjacência à primeira forma verbal (não se pode dizer; pode-se sempre dizer), em relação aos demais pronomes, comumente ligados à segunda forma verbal.

As tendências da ordem dos clíticos pronominais verificadas em Vieira (2002) puderam ser comparadas, posteriormente (nos trabalhos da equipe, com diferentes fontes de dados), àquelas que foram detectadas em outros estudos sobre o fenômeno: (i) Morito Machado $(2006)^{3}$, referente à aprendizagem da colocação na escrita escolar; (ii) Nunes $(2009,2014)$, referente aos usos no PB e no PE em jornais dos séculos XIX e XX, seja com os clíticos em geral, em 2009, seja exclusivamente com o pronome "se", em 2014; (iii) Santos, D. (2010, 2015), referente aos usos na literatura brasileira, durante todo o século XX, em 2010, e na história da constituição da norma "predicada" e "praticada" na virada do século XIX para o XX, em 2015; (iv) Peterson (2010), considerando o comportamento do fenômeno em cartas de leitores em diferentes jornais no Rio de Janeiro; (v) Rodrigues-Coelho (2011), em análise de redações ao longo dos anos escolares; (vi) Vieira (2011, 2016), sobre o fenômeno em variedades populares do PE, em 2011, e em dados comparados do PB, do PE e do PST (Português de São Tomé), em 2016; (vi) Corrêa (2012), sobre o uso em complexos verbais na fala brasileira contemporânea.

O conjunto desses trabalhos permitiu, em linhas gerais, demonstrar, no plano diacrônico: (i) a trajetória percorrida pelo fenômeno a partir de dados escritos, desde o século XIX até os dias atuais, nas variedades brasileira e europeia, configurando o provável traçado da mudança em tempo real de longa duração; (ii) o comportamento particular de dados consoante o gênero textual, como anúncios, notícias, editoriais, no domínio jornalístico (além do veículo em questão), e contos, no domínio literário; e (iii) a proposta de que a mudança linguística detectada nos dados brasileiros - com entrada da inovadora próclise à segunda forma verbal - não afetou igualmente o clítico se indeterminador, que se mantém, quando produzido, na adjacência à primeira forma verbal.

3 Essa minha primeira orientação foi na verdade uma coorientação, na companhia de Silvia Brandão, que também me ensinou a orientar. 
Quanto a dados sincrônicos contemporâneos do Português, foi possível realizar: (i) a descrição sistemática de dados de fala e/ou de escrita em variedades brasileira, europeia, moçambicana e são-tomense, demonstrando opções claramente diferenciadas na fala, mas evidente aproximação (embora com particularidades, sobretudo em função dos gêneros em questão) na escrita; (ii) a postulação de regras com diferentes estatutos, consoante a variedade, detectando uma regra semicategórica de colocação na fala brasileira, em oposição à colocação variável nas falas europeia, embora com condicionamentos rígidos para o fenômeno em função do contexto morfossintático, e moçambicana e são-tomense, com ampla variação em mesmos contextos sintáticos, sobretudo no que se refere à ênclise em contexto com os chamados elementos proclisadores.

No âmbito dos já referidos estudos da concordância verbal quanto à caracterização de variedades internacionais do Português (cf. BRANDÃO; VIEIRA, 2012; BARRETO, 2014; VIEIRA; BAZENGA, 2013, 2015; VIEIRA, 2014; VIEIRA; BRANDÃO, 2014; VIEIRA, 2015), foi possível estabelecer que as variedades do Português têm feições particulares, e que essas feições permitem traçar tendências tipológicas quanto ao fenômeno em questão. Nesse sentido, os resultados contrastivos da concordância também permitiram observar que $\mathrm{PB}$ e $\mathrm{PE}$ não compartilham com as europeias o mesmo tipo de regra.

De todo o exposto, é inevitável concluir que o PE não partilha o mesmo perfil quantitativo nem qualitativo do PB vernacular. Restrições sociais, como escolaridade e perfil urbano/rural, e, sobretudo, a presença ou a ausência de dados sem concordância numa variedade de contextos estruturais possibilitam estabelecer condições exclusivamente brasileiras da ausência da marca de pluralidade. Ademais, dados categóricos e semicategóricos de concordância, associados a dados variáveis exclusivamente nos contextos de concordância semântica em construções com a gente, igualmente particularizam o PE. Em outras palavras, os perfis quantitativo e qualitativo dos padrões de concordância verificados e discutidos neste artigo permitem afirmar que PB e PE configuram tipos linguísticos distintos ou assumem parâmetros gramaticais diferentes da marcação de número plural. (VIEIRA; BRANDÃO, 2014, p. 107-108)

De outro lado, o caráter intermediário da variedade são-tomense (92\%) entre as distintas opções das variedades brasileiras e portuguesas - pôde também ser atestado ${ }^{4}$. Enquanto o Português do Brasil exibe uma regra claramente variável

4 A pesquisa de Mestrado da orientanda Karen Christina da Silva Pissurno (2017) sobre a concordância verbal, em amostra recentemente coletada em Maputo por ela e por Silvia Rodrigues Vieira, permite considerações mais precisas sobre esse fenômeno em dados da variedade moçambicana do Português. 
(78\%), afetando diversas estruturas morfossintáticas, e o Português Europeu apresenta índices semicategóricos (99\%) de marcação de plural, com restritas estruturas relacionadas à não marcação de pluralidade, a variedade são-tomense posiciona-se em porção intermediária de modo a apresentar uma regra variável, embora em menor extensão do que a verificada na brasileira.

Nesse sentido, os resultados apresentados, seja no âmbito da colocação pronominal, seja no da concordância verbal, têm permitido somar evidências que vão ao encontro da postulação de um "continuum afrobrasileiro", proposto por Petter $(2008,2010)$. Segundo a autora, as diferentes situações de contato, em épocas diversas, permitiram observar resultados semelhantes em relação a determinados aspectos e níveis gramaticais. Nesse sentido, os estudos empreendidos oferecem contribuição a investigações dessa natureza, visto que procedem ao levantamento de dados obtidos em estudos sobre variedades do Português no Brasil, em Portugal, em São Tomé e em Moçambique.

\section{ANÁLISE VARIACIONISTA E A INTERFACE MORFOSSINTAXE- FONÉTICA (OU: SILVIA BRANDÃO, DA FONETICISTA EM MIM)}

Desde o controle da variável saliência fônica, proposta por Lemle; Naro (1977), a interface dos planos morfossintático e fonético-fonológico mostrou-se produtiva nos estudos da concordância. No caso da trajetória dos estudos de Vieira, entretanto, foi no tema da ordem dos clíticos pronominais que a face fonética foi mais detalhadamente investigada em primeiro lugar.

A antiga correlação entre a posição dos clíticos e sua inclinação (clisis) à direita ou à esquerda em função do caráter acentual das sílabas e/ou de motivações rítmicas foi investigada por Vieira (2002). A autora procedeu ao levantamento das características prosódicas, quanto a duração, intensidade e frequência fundamental, que podem motivar diferentes padrões de ligação fonológica dos clíticos nas variedades brasileira e europeia do Português, de modo a responder à seguinte questão: quais os parâmetros de base acústica que efetivamente atuam no condicionamento da ordem dos clíticos em Português?

Valendo-se do arcabouço teórico-metodológico da Fonética Acústica, segundo os recursos do Programa Computacional CSL (Computerized Speech Lab), Vieira (2002) estudou o comportamento dos pronomes em dados do PE e do PB, procedendo (i) à determinação da duração, da intensidade e da frequência fundamental, viabilizada pelo tratamento dos dados, e (ii) à ressíntese dos enunciados. Além de descrever o caráter acentual dos clíticos, se mais pretônico ou postônico, o recurso da manipulação dos fatores acústicos constitui um recurso essencial para a delimitação precisa das diferenças prosódicas. O procedimento consiste em submeter ao programa o enunciado de uma dada variedade e transformá-lo, por meio da alteração de parâmetros prosódicos, em outro. Alterados os parâmetros e, consequentemente, adquirido 
o enunciado em nova versão, testa-se a eficiência da "transformação" do enunciado por meio da realização de testes perceptivos com falantes do Português quanto ao reconhecimento da ligação do clítico - se à direita ou à esquerda.

Os resultados apresentados em Vieira (2002) permitiram afirmar que, em termos acústicos:

(i) o pronome átono do PB apresenta, quanto à duração e à intensidade, as mesmas configurações de uma sílaba pretônica vocabular; o pronome átono do PE assume, quanto à duração e à intensidade, as características de uma sílaba postônica/pretônica vocabular.

Por meio de comparação de pretônicas clíticas e vocabulares, como em enunciados do tipo <como me sangra a alma eu não entendo/como miçanga acalma eu não entendo $>$, ficou evidente a semelhança da sílaba do pronome átono ( $\underline{\text { me sangra) }}$ com a sílaba pretônica vocabular (miçanga) no PB. No caso do PE, foi possível observar a menor duração e a menor intensidade do pronome em relação ao do PB.

(ii) a ligação fonológica do pronome átono no PB dá-se para a direita, enquanto o PE assume o parâmetro da ligação fonológica para a esquerda; e

(iii) o parâmetro acústico do acento que determina a cliticização do pronome à esquerda é, essencialmente, a duração - abreviada no PE -, atuando, em segundo plano, a intensidade - menor no PE.

Os resultados anteriormente, adquiridos pela medição dos parâmetros acústicos do acento e pelo recurso da síntese da fala, ficaram evidentes por meio do julgamento dos ouvintes nos testes de percepção.

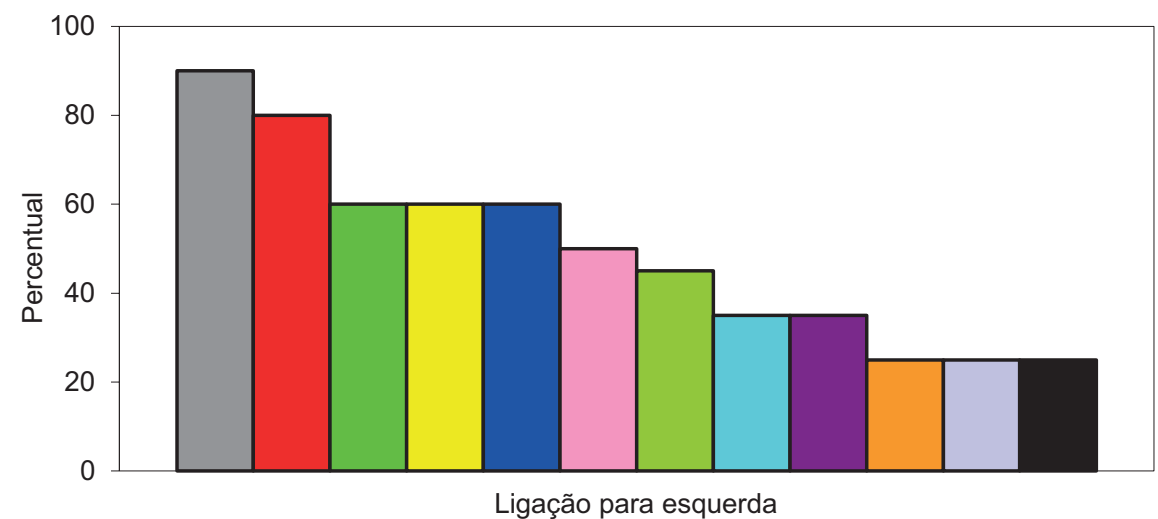

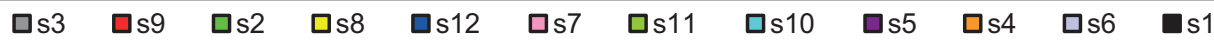

Gráfico 1 Percepção da ligação fonológica do pronome à esquerda, segundo os percentuais dos votos em testes de percepção auditiva em relação a doze contextos: enunciado original brasileiro (s1) e enunciados manipulados segundo recurso de síntese de fala (s2 a s10).

Fonte: Vieira (2002: 378). 
Quadro 1 Graus de percepção da ligação do clítico para a esquerda.

\begin{tabular}{|l|}
\hline GRAUS DE PERCEPÇÃo DA LIGAÇÃo PARA ESQUERDA \\
\hline GRAU 1 = versão original (S1) / redução leve da intensidade (S4) / FO: de descendente a ascendente (S6) \\
\hline GRAU 2= redução forte da intensidade (S5) / F0: de descendente a ascendente e redução leve da duração (S10) \\
\hline GRAU 3= F0: de descendente a ascendente e redução leve da intensidade (S11) / redução leve de duração e \\
intensidade (S7) \\
GRAU 4= redução leve da duração (S2) / redução leve da duração e forte da intensidade (S8) / F0: de descendente \\
a ascendente e redução leve de duração e intensidade (S12) \\
\hline GRAU 5= redução forte da duração e leve da intensidade (S9) / redução forte da duração (S3) \\
\hline
\end{tabular}

Fonte: Vieira (2002: 378).

Os resultados representados no Gráfico 1 permitem afirmar que: (i) o parâmetro de cliticização à esquerda está associado, em primeiro plano, ao parâmetro acústico da duração: a redução forte do tempo da sílaba do clítico acarreta a escolha quase categórica desse parâmetro (80/90\%); a redução leve do tempo da sílaba do clítico motiva a opção pelo parâmetro em mais da metade dos casos (60\%); e (ii) o parâmetro acústico da intensidade atua moderadamente na determinação do parâmetro: a redução forte da intensidade faz aumentar o índice de percepção do parâmetro à esquerda (de 25 para 35\%); ademais, associada a outros dois parâmetros, a redução da intensidade do clítico aparece também nos graus intermediários ( 3 e 4). Observe-se que, se a alteração for apenas uma redução leve da intensidade, o enunciado é percebido da mesma forma que o original.

Dando continuidade ao desenvolvimento da metodologia proposta em Vieira (2002), Corrêa (2012) realizou experimentos mais detalhados, diferenciando-se do trabalho anterior nos seguintes pontos: (i) observou, além de intensidade e duração, as frequências formânticas 1 e 2 (e não a F0), para que fosse possível o controle da qualidade vocálica da sílaba em questão; (ii) valeu-se de tratamento estatístico (por meio do Programa R); e (iii) controlou detalhadamente o comportamento do pronome se, reflexivo ou indeterminador, para os quais tinha hipóteses particulares.

No que se refere ao caráter acentual das sílabas, Corrêa (2012) constatou que, no caso de pares efetivamente homófonos, as diferenças entre sílaba clítica e pretônica vocabular não são expressivas quanto à intensidade, e são praticamente inexistentes quanto à duração. Em termos gerais, os resultados relativos à vogal presente nos pronomes átonos e nas sílabas átonas vocabulares apresentaram semelhanças entre esses segmentos, sobretudo no caso de se tratar de vogal alta, dada a identidade de seus traços. 
Quanto ao tipo de clítico, os resultados revelam que a forma se se particulariza em relação aos demais pronomes. Ao que tudo indica, a ligação enclítica ao verbo auxiliar seria a prototípica do se indeterminador (pode-se dirigir a $100 \mathrm{~km}$ por hora), enquanto a proclítica seria associada à ligação sintática que o se reflexivo estabelece com o verbo temático (você pode se-dirigir ao balcão). A instabilidade dos resultados para o pronome se fortalece essa hipótese no estudo de Corrêa (2012).

No que se refere aos testes de percepção dos enunciados manipulados acusticamente, tendências semelhantes às observadas em Vieira (2002) puderam ser verificadas nos resultados obtidos em CORREAA (2009, 2012). Em síntese, os resultados, relativos tanto ao pronome me quanto ao se, convergem para a conclusão sistematizada na Figura 2, proposta pela autora.

\begin{tabular}{|l|l|l|}
\hline + Próclise / - Ênclise & & \multicolumn{1}{c|}{ - Próclise / + Ênclise } \\
\hline Versão original, & Redução "forte" da intensidade e/ou redução & Redução "forte" da duração \\
Fo ascendente e/ou redução & "leve" da duração, combinada(s) ou não à Fo & e/ou redução "leve" da \\
"leve" da intensidade. & ascendente. & intensidade, combinadas ou \\
& & não à Fo ascendente. \\
\hline
\end{tabular}

Figura 2 Representação escalar dos resultados dos testes de percepção auditiva de Corrêa (2009).

Fonte: Corrêa (2009: 937)5.

Conforme sintetizam Vieira; Corrêa (2017, p. 92):

De modo geral e considerando as pesquisas aqui contempladas, pode-se afirmar, a título de sistematização, que existem fortes indícios de que o clítico pronominal na variedade brasileira do Português seja prototipicamente proclítico. Houve semelhanças entre sílaba clítica e sílaba pretônica vocabular tomando por base os parâmetros acústicos de duração e intensidade, semelhanças não tão evidentes no caso do pronome $s e-$ a depender de sua função - e em pares com diferença na qualidade vocálica.

A interface fonética-morfossintaxe, aprofundada no tratamento da ordem dos clíticos pronominais, também tem sido investigada, sob outras bases e metodologias, na abordagem da concordância verbal de $3^{\mathrm{a}}$ pessoa.

5 A linha tracejada pretende representar o limite tênue entre as duas categorias. 
Nesse caso, importa caracterizar detalhadamente a pronúncia das desinências número-pessoais, não só para estabelecer se efetivamente se trata de expressão de pluralidade ou não, mas também se as diferenças entre as formas verbais singular e plural configuram os graus de saliência que tradicionalmente têm sido contemplados nos estudos sobre o tema.

Primeira iniciativa nessa direção pôde ser observada no trabalho de Barreto (2014), em que a autora levantou a pronúncia de todas as formas verbais de $3^{a}$ pessoa plural na variedade lisboeta do Português, demonstrando que a pronúncia ditongada do plural constitui a regra de uso. Considerando o propósito de realização de análise contrastiva entre as variedades do Português, Vieira; Brandão; Gomes (2015) fazem ampla revisão bibliográfica e lançam diretrizes para a caracterização morfofonológica das desinências de número, em andamento ${ }^{6}$, e, consequentemente, para o tratamento da variável saliência fônica.

\section{ANÁLISE VARIACIONISTA E SOCIOLINGUÍSTICA EDUCACIONAL (OU: SILVIA BRANDÃO, DA PROFESSORA EM MIM)}

Uma última interface da Sociolinguística também constituiu foco de interesse desde o trabalho sobre a concordância de $3^{a}$ pessoa plural na fala dos analfabetos do Norte fluminense (VIEIRA, 1995). Após o tratamento do tema em termos variacionistas, desenvolve-se um capítulo específico sobre a abordagem didática dos resultados das variáveis relevantes ao condicionamento do fenômeno, de modo a aplicar a proposta feita por Lemle; Naro (1977), de que o conjunto de fatores desfavorecedores da marcação de plural (expostos no Quadro 2) deveria ser priorizado nas atividades pedagógicas, para a necessária ampliação de repertório por parte dos estudantes. Nesse sentido, propõe a autora:

Pela visualização dos fatores que propiciam a ocorrência de marca, ficam estabelecidos os contextos pelos quais se deve iniciar o ensino da concordância. E, pela observação dos fatores que levam ao cancelamento da marca, evidenciam-se as construções que devem ser priorizadas nos exercícios propostos. (VIEIRA, 1995, p. 142)

6 No caso da concordância verbal de $3^{\text {a }}$ pessoa plural nos dados do PB, Jéssica Araújo Moraes da Rocha tem-se ocupado, em nível de iniciação científica, da caracterização detalhada das desinências em questão. 
Quadro 2 Variáveis significativas para o condicionamento da regra de cancelamento: fatores desfavorecedores e favorecedores.

\begin{tabular}{|l|l|l|}
\hline \multicolumn{1}{|c|}{ VARIÁVEIS } & $\begin{array}{c}\text { CONTEXTOS QUE PROPICIAM A } \\
\text { OCORRÊNCIA DE MARCA } \\
\text { DE NÚMERO }\end{array}$ & $\begin{array}{c}\text { CONTEXTOS QUE PROPICIAM } \\
\text { O CANCELAMENTO DA MARCA } \\
\text { DE NÚMERO }\end{array}$ \\
\hline saliência fônica & $\begin{array}{c}\text { formas verbais de alto nível de } \\
\text { saliência }\end{array}$ & $\begin{array}{c}\text { formas verbais de baixo nível de } \\
\text { saliência }\end{array}$ \\
\hline paralelismo clausal & v. prec. de SN sujeito marcado & v. prec. de SN sujeito não marcado \\
\hline paralelismo discursivo & v. prec. de v. com marca de plural & $\begin{array}{l}\text { v. prec. de v. com marca de plural } \\
\text { ou de 3 }{ }^{\text {a }} \text { p. do sing. }\end{array}$ \\
\hline posição do sujeito & sujeito anteposto & sujeito posposto \\
\hline animacidade & sujeito animado & sujeito inanimado \\
\hline distância entre SN e SV & SN sujeito próximo do SV & SN sujeito distante do SV \\
\hline
\end{tabular}

Fonte: Vieira (1995: 242).

Oferecendo total acolhida à proposta de Vieira - que acabou por organizar, com a participação de colegas da área, cursos de extensão específicos sobre a relação gramática e ensino -, Brandão integrou o projeto de divulgação das aulas dos referidos cursos, projeto que resultou na publicação do livro Ensino de gramática: descrição e uso (VIEIRA; BRANDÃO, 2007). Com base nessa publicação, foi possível reunir, para a área do ensino, informações atualizadas acerca de objetos gramaticais teóricos (termos da oração, períodos compostos, expressão de grau, dentre outros) e do comportamento de fenômenos variáveis (quadro pronominal, concordância verbal, concordância nominal, colocação pronominal).

Com o objetivo de sistematizar o comportamento dos dados também no âmbito das variedades cultas do Português do Brasil, em suas modalidades falada e escrita (+ ou - monitorada), Vieira; Freire (2014) propõem contínuos de variação considerando diversos fenômenos morfossintáticos. Desse modo, oferecem aos profissionais de ensino evidências de que a chamada "norma culta" constitui, na realidade, diversas expressões variáveis em função do contínuo fala-escrita e de diferentes graus de monitoração estilística.

Em projeto recente vinculado à rede municipal de ensino do Rio de Janeiro e na participação nos cursos do Mestrado Profissional em Letras/PROFLETRAS, tem sido possível dar continuidade às reflexões inauguradas em 1995 e, assim, enveredar pela abordagem metodológica de fenômenos gramaticais em sala de aula. Nesse sentido, Vieira (2017) propõe - com base no planejamento nacional 
da disciplina Gramática, Variação e Ensino, do PROFLETRAS - que a abordagem do componente gramatical nas aulas de Português como língua materna se aproprie de investimentos em três frentes de trabalho, que podem ser considerados individualmente ou em parceria: (i) ensino de gramática como atividade reflexiva para explicitação do conhecimento linguístico natural; (ii) ensino de gramática como reconhecimento dos efeitos expressivos do componente linguístico, nos níveis micro e/ou macroestrutural do texto; e (iii) ensino de gramática como atividade promotora do conhecimento de regras variáveis.

Com base na referida proposta, os trabalhos acadêmicos desenvolvidos nas orientações ${ }^{7}$ têm buscado atualizar o conjunto de informações necessárias à prática pedagógica (Cf. PIMENTA, 2013; SANTOS, J, 2015; SANTANA, 2016) e propor sequências de atividades que visem a articular os três referidos eixos de trabalho. Nessa perspectiva, foram trabalhados recentemente os temas variáveis da indeterminação do referente (SOUZA, 2015), da expressão de segunda pessoa (GOUVÊA, 2016) e da concordância verbal de $3^{\mathrm{a}}$ pessoa (CHAGAS, 2016). Com base em revisão da literatura, os referidos trabalhos apresentam propostas de intervenção em sala de aula a partir de um conjunto de atividades linguísticas, epilinguísticas e metalinguísticas, que objetivam desenvolver o conhecimento sobre o tema gramatical em questão, articulando-o à produção de sentidos e à manifestação de regras variáveis.

\section{CONSIDERAÇÕES FINAIS}

Espero ter cumprido o objetivo inicialmente formulado para este texto: o de reconhecer que, em cada etapa da trajetória por mim percorrida, se encontram presentes, direta ou indiretamente, as influências da orientação recebida, do Mestrado aos dias de hoje, por Silvia Figueiredo Brandão. Sei que o desafio da proposta me obriga a cumpri-lo apenas parcialmente, por não caber, dada a sua própria natureza, no espaço de um texto acadêmico.

Além dos trabalhos já concluídos, cabe destacar as atividades desenvolvidas por Francis de Melo Valadares, na descrição das formas de tratamento endereçadas a Deus no discurso religioso; Luiz Felipe da Silva Durval, na apreciação crítica do material desenvolvido pela Secretaria Municipal de Educação para o segundo segmento do Ensino Fundamental e no planejamento de sequência didática; e Monique Débora Alves de Oliveira, na elaboração de oficinas de variação linguística com atividades lúdicas. Vieira (2017) apresenta reflexões com base em propostas didáticas, em e-book organizado a partir do desenvolvimento do Projeto "Gramática, variação e ensino: diagnose e propostas pedagógicas”, financiado pela FAPERJ (Edital Apoio à melhoria do ensino em Escolas da Rede Pública sediadas no Estado do Rio de Janeiro - 2014). 
Descrições e análises, descrições para análises. Da concordância verbal e da ordem dos clíticos pronominais a diversos fenômenos morfossintáticos. Dialectologia, Sociolinguística, Abordagem contrastiva de variedades do Português. Morfossintaxe, Fonética... interfaces. De todas elas, sobressaem, sem dúvida, as extra-acadêmicas, cujas feições se refletem na trajetória das análises científicas, das orientações recebidas às transmitidas, da descrição de dados à elaboração de estratégias pedagógicas.

Vale a pena repetir: uma significativa trajetória de aprendizado e partilha, fruto de um crescente desejo de dar conta do objeto em análise e fazer sempre mais e melhor. Muito obrigada, Silvia Brandão, por tudo que me ensinou!

\section{REFERÊNCIAS BIBLIOGRÁFICAS}

BARRETO, Fernanda Villares Vianna. A concordância verbal de $3^{a}$ pessoa do plural no Português Europeu. 2014. Dissertação (Mestrado em Letras Vernáculas) - Faculdade de Letras, Universidade Federal do Rio de Janeiro, Rio de Janeiro, 2014.

BRANDÃO, Silvia Figueiredo. Patterns of agreement within the Noun Phrase. Journal of Portuguese Linguistics 12 (2), p. 51-100, 2013.

; VIEIRA, Silvia Rodrigues. Concordância nominal e verbal: contribuições para o debate sobre o estatuto da variação em três variedades urbanas do Português. Alfa 56 (3), p. 1035-1064, 2012.

CHAGAS, Danieli Silva. Concordância verbal de terceira pessoa: descrição Sociolinguística e proposta pedagógica em turmas do Ensino Fundamental. 2016. Dissertação (Mestrado Profissional em Letras - PROFLETRAS) - Faculdade de Letras, Universidade Federal do Rio de Janeiro, Rio de Janeiro, 2016.

CORRÊA, Cristina Márcia Monteiro de Lima. Cliticização fonológica em variedade brasileira do Português. In: HORA, Dermeval da (org.). ABRALIN 40 anos. João Pessoa: Ideia, 2009, p. 932-938.

Cliticização pronominal na região metropolitana do Rio de Janeiro: a interface Sintaxe-Fonologia. 2012. Dissertação (Mestrado em Língua Portuguesa) - Faculdade de Letras, Universidade Federal do Rio de Janeiro, Rio de Janeiro, 2012.

GOUVÊA, Isabela Passos. Variação das formas interlocutivas de segunda pessoa: estratégias pedagógicas. 2016. Dissertação (Mestrado Profissional em Letras - PROFLETRAS) - Faculdade de Letras, Universidade Federal do Rio de Janeiro, Rio de Janeiro, 2016.

GRACIOSA, Diva. Concordância verbal na fala culta carioca. 1991. Dissertação (Mestrado em Letras Vernáculas) - Faculdade de Letras, Universidade Federal do Rio de Janeiro, Rio de Janeiro, 1991.

LEMLE, Miriam; NARO, Anthony Julius. Competências básicas do Português. Rio de Janeiro: Relatório final de pesquisa apresentado às instituições patrocinadoras Fundação Movimento Brasileiro (MOBRAL) e Fundação Ford, 1977. 
LUCCHESI, Dante; BAXTER, Alan; SILVA, Jorge Augusto Alves da. A concordância verbal. In: LUCCHESI, Dante; BAXTER, Alan; RIBEIRO, Ilza (orgs.). O Português afro-brasileiro. Salvador: EDUFBA, 2009, p. 331-371.

MACHADO VIEIRA, Marcia dos Santos; VIEIRA, Silvia Rodrigues. A representação sócio-geolinguística de fenômenos morfossintáticos: nós/a gente e concordância verbal. In: CUNHA, Cláudia de Souza (org.). Estudos geo-sociolinguísticos. Rio de Janeiro: Pós-graduação em Letras Vernáculas, 2006, p. 99-112.

MORITO MACHADO, Ana Carla. O uso e a ordem dos clíticos na escrita de estudantes da cidade do Rio de Janeiro. 2006. Dissertação (Mestrado em Letras Vernáculas) Faculdade de Letras, Universidade Federal do Rio de Janeiro, Rio de Janeiro, 2006.

NARO, Anthony Julius. The social and structural dimensions of a syntactic change. Language 57, p. 63-98, 1981.

; SCHERRE, Maria Marta Pereira. Origens do Português brasileiro. São Paulo: Parábola Editorial, 2007.

NUNES, Carla da Silva. Um estudo sobre a ordem dos cliticos em complexos verbais no PB e no PE. 2009. Dissertação (Mestrado em Letras Vernáculas) - Faculdade de Letras, Universidade Federal do Rio de Janeiro, Rio de Janeiro, 2009.

A ordenação do clítico "se" em complexos verbais nas produções escritas do Brasil e de Portugal nos séculos XIX e XX segundo a perspectiva sociolinguística. 2014. Tese (Doutorado em Letras Vernáculas) - Faculdade de Letras, Universidade Federal do Rio de Janeiro, Rio de Janeiro, 2014.

PETTER, Margarida Maria Taddoni. Línguas africanas no Brasil. África (USP) 27/28, p. 63-89, 2010.

. Uma hipótese explicativa do contato entre o Português e as línguas africanas. Papia 1, p. 9-19, 2008.

PETERSON, Márcia Saldanha. A ordem dos cliticos pronominais em lexias verbais simples e complexas em cartas de leitor: uma contribuição da Sociolinguística Variacionista. 2010. Dissertação (Mestrado em Letras Vernáculas) - Faculdade de Letras, Universidade Federal do Rio de Janeiro, Rio de Janeiro, 2010.

PIMIENTA, P. C. S. La segunda persona de singular en el Português de Rio de Janeiro: variación en la relación gramatical de objeto directo. 2013. Dissertação (Maestria em Linguística Aplicada) - Universidad de Guadalajara, Guadalajara, 2013.

PISSURNO, Karen Cristina da Silva. A concordância verbal de terceira pessoa do plural na variedade moçambicana do Português: uma abordagem sociolinguística. 2017. Dissertação (Mestrado em Letras Vernáculas). - Faculdade de Letras, Universidade Federal do Rio de Janeiro, Rio de Janeiro, 2017.

RODRIGUES-COELHO, Adriana Lopes. A ordem dos clíticos pronominais: uma análise sociolinguística da escrita escolar do Rio de Janeiro. 2011. Dissertação (Mestrado em Letras Vernáculas) - Faculdade de Letras, Universidade Federal do Rio de Janeiro, Rio de Janeiro, 2011. 
SANTANA, Juliana Magalhães Catta Preta de. Diagnose e ensino de pronomes: um estudo sobre a retomada anafórica do objeto direto de terceira pessoa no Português Brasileiro. 2016. Dissertação (Mestrado em Letras Vernáculas) - Faculdade de Letras, Universidade Federal do Rio de Janeiro, Rio de Janeiro, 2016.

SANTOS, Daniely Cassimiro de Oliveira. Análise diacrônica da colocação pronominal nas variedades brasileira e europeia do Português Literário: um estudo segundo o conjugado "Variação-Mudança \& Cliticização". 2010. Dissertação (Mestrado em Letras Vernáculas) - Faculdade de Letras, Universidade Federal do Rio de Janeiro, Rio de Janeiro, 2010.

Do predicado ao praticado na constituição da norma brasileira [1870-1929]: a colocação pronominal. 2015. Tese (Doutorado em Letras Vernáculas) - Faculdade de Letras, Universidade Federal do Rio de Janeiro, Rio de Janeiro, 2015.

SANTOS, Juliana da Costa. O comportamento das estratégias de relativização na escrita culta jornalística brasileira. 2015. Dissertação (Mestrado em Letras Vernáculas) - Faculdade de Letras, Universidade Federal do Rio de Janeiro, Rio de Janeiro, 2015.

SCHERRE, Maria Marta; NARO, Anthony Julius. A concordância de número no Português do Brasil: um caso típico de variação inerente. In: HORA, Dermeval da (org.). Diversidade linguística no Brasil. João Pessoa: Ideia, 1997, p. 93-114.

SOUZA, Daniela da Silva de. Estratégias de indeterminação do sujeito: uma proposta pedagógica para o ensino de gramática. 2015. Dissertação (Mestrado Profissional em Letras - PROFLETRAS) - Faculdade de Letras, Universidade Federal do Rio de Janeiro, Rio de Janeiro, 2015.

VIEIRA, Maria de Fátima. A cliticização pronominal em lexias verbais simples e em complexos verbais no Português Europeu oral contemporâneo: uma investigação sociolinguística. 2011. Dissertação (Mestrado em Letras Vernáculas) - Faculdade de Letras, Universidade Federal do Rio de Janeiro, Rio de Janeiro, 2011.

. A ordem dos clíticos pronominais nas variedades urbanas europeia, brasileira e são-tomense: uma análise sociolinguística do Português no início do século XXI. 2016. Tese (Doutorado em Letras Vernáculas) - Faculdade de Letras, Universidade Federal do Rio de Janeiro, Rio de Janeiro, 2016.

VIEIRA, Silvia Rodrigues. Concordância verbal: variação em dialetos populares do Norte Fluminense. 1995. Dissertação (Mestrado em Letras Vernáculas) - Faculdade de Letras, Universidade Federal do Rio de Janeiro, Rio de Janeiro, 1995.

- Colocação pronominal nas variedades europeia, brasileira e moçambicana: para a definição da natureza do clítico em Português. 2002. Tese (Doutorado em Língua Portuguesa) - Faculdade de Letras, Universidade Federal do Rio de Janeiro, Rio de Janeiro, 2002.

. Sociolinguística e ensino de Português: para uma pedagogia da variação linguística. In: MARTINS, Marco Antônio; TAVARES, Maria Alice (orgs.). Contribuições da Sociolinguística e da Linguística Histórica para o ensino de Lingua Portuguesa. Natal: EDUFRN, 2013, p. 53-90. (Coleção Ciências da Linguagem Aplicadas ao Ensino, vol. V) 
. Entre o variável e o categórico: a concordância verbal e a colocação pronominal em variedades do Português In: REZENDE, Letícia Marcondes; NADIN, Odair Luiz; MENDONÇA, Marina Célia; ZAVAGLIA, Claudia; BRUNELLI, Anna Flora (orgs.). A interdisciplinaridade e a especificidade linguística: teorias e práticas. Araraquara; São Paulo: FCL-Unesp Laboratório Editorial; Cultura Acadêmica, 2014, p. 75-98. (Série Trilhas Linguísticas, 26)

(org.). A concordância em variedades do Português: a interface Fonética-Morfossintaxe. Rio de Janeiro: Vermelho Marinho, 2015.

. Três eixos para o ensino de gramática: uma proposta experimental. In: NORONHA, Claudianny Amorim; SÁ JR., Lucrécio Araújo de (orgs.). Escola, ensino e linguagem [recurso eletrônico]. Natal-RN, EDUFRN, 2017. <http://repositorio.ufrn.br>.

; BAZENGA, Aline. Patterns of third person verbal agreement. Journal of Portuguese Linguistics 12 (2), p. 7-50, 2013.

; BAZENGA, Aline. A concordância da terceira pessoa plural: padrões em variedades do Português. In: VIEIRA, Silvia Rodrigues (org.). A concordância em variedades do Português: a interface Fonética-Morfossintaxe. Rio de Janeiro: Vermelho Marinho/ FAPERJ, 2015, p. 29-75.

; BRANDÃO, Silvia Figueiredo (orgs.). Ensino de gramática: descrição e uso. São Paulo: Contexto, 2007.

; BRANDÃO, Silvia Figueiredo. Tipologia de regras linguísticas e estatuto das variedades/línguas: a concordância em Português. Linguística 30 (2), p. 81 -112, 2014. le, 2015.

; BRANDÃO, Silvia Figueiredo (orgs.). Cuadernos de la ALFAL 7, Santiago/Chi-

; CORRÊA, Cristina Márcia Monteiro de Lima. Colocação pronominal no Português do Brasil: a contribuição de estudos de percepção auditiva. Letras de hoje 52 (1), p. 87-96, 2017.

; FREIRE, Gilson Costa. Variação morfossintática e ensino de Português. In: MARTINS, Marco Antônio; VIEIRA, Silvia Rodrigues; TAVARES, Maria Alice (orgs.). Ensino de Português e Sociolinguística. São Paulo: Contexto, 2014, p. 81-114. 
